\title{
Green Synthesis of Novel Jasmine Bud-Shaped Copper Nanoparticles
}

\author{
Malathi Sampath, Ramya Vijayan, Ezhilarasu Tamilarasu, \\ Abiraman Tamilselvan, and Balasubramanian Sengottuvelan \\ Department of Inorganic Chemistry, Guindy Campus, University of Madras, Chennai 600 025, India \\ Correspondence should be addressed to Balasubramanian Sengottuvelan; bala2010@yahoo.com
}

Received 22 July 2013; Accepted 12 December 2013; Published 13 February 2014

Academic Editor: Mahi R. Singh

Copyright (C) 2014 Malathi Sampath et al. This is an open access article distributed under the Creative Commons Attribution License, which permits unrestricted use, distribution, and reproduction in any medium, provided the original work is properly cited.

Novel jasmine bud-shaped copper nanoparticles were synthesized by a green chemical reduction method using polyvinylpyrrolidone (PVP) as a capping agent, L-ascorbic acid (AA) as a reducing agent as well as antioxidant agent, isonicotinic acid hydrazide (INH) as a reducing agent, and water as a solvent at $60-70^{\circ} \mathrm{C}(\mathrm{pH}-7)$ in the presence of air. The UV-Vis absorption maximum obtained is $573 \mathrm{~nm}$. The crystal lattice (fcc) structure of $\mathrm{Cu}$ Nps was confirmed by X-ray diffraction (XRD). The novel jasmine bud shape was visualized in a transmission electron microscope (TEM). The height of single copper nanobud was $6.41 \mathrm{~nm}$ as measured by atomic force microscope (AFM). The average particle size $6.95 \mathrm{~nm}$ is obtained by XRD results. Antibacterial activity of the Cu nanobuds was evaluated by testing against Gram-negative (Escherichia coli) and Gram-positive (Staphylococcus aureus) bacteria.

\section{Introduction}

Nanotechnology is one of the fast developing technologies and its products are very useful in all fields, because of their small size $\left(10^{-9} \mathrm{~nm}\right)$ and large surface area. Nanoparticles offer a larger surface-to-volume ratio and a higher concentration of partially coordinated surface sites than the corresponding bulk materials. The unique properties of nanoparticles are due to a strong interplay between elastic, geometric, and electronic parameters. The result of these features is often improved by physical and chemical properties compared to that of bulk material [1]. The research on nanoparticles has gathered wide attention during the last decade because of their unusual and size-dependent optical [2], magnetic [3], electronic [4], and chemical [5, 6] properties. To fully utilize these properties, the size and shape must be well controlled.

Copper nanoparticles are known to be extremely sensitive to oxygen, and therefore there are several problems related to the stability and oxidation resistance. The synthesis of copper nanoparticles has not been as widely explored as that of many other metals due to the easily oxidizable nature of copper, which is enhanced in nanoscale structures. Yet, several methods have been reported. Copper nanoparticles have been successfully synthesized, for example, by $\gamma$-radiolysis [7], laser irradiation [8], thermal decomposition $[9,10]$, thiol-induced reduction in supercritical water [11], reduction in microemulsions [12], and reverse micelles [13], vapor deposition [14], sonoelectrochemical [15], flame spray [16], and chemical reduction [17-19] methods. These methods are time-consuming and are carried out by using expensive instruments. Yanase and Komiyama [20] have examined the mechanism and kinetics of copper nanoparticles oxidation and reduction with UV-Vis spectroscopy by recycling glasssupported particles between oxygen and hydrogen atmospheres. Wu and Chen [21] have used CTAB as capping ligand for the synthesis of small $(5.1 \mathrm{~nm}) \mathrm{Cu}$ nanoparticles, which they have reported to be stable in aqueous solution for months. Copper nanoparticles are found to aggregate severely without proper protection and they oxidize easily in air. Recent studies [22] show that copper nanoparticles are, at room temperature, only oxidized from the surface. Although gold and silver withstand oxidation better than copper, copper is still a very attractive candidate for future conducting materials because of its abundance and cheapness. The problems of aggregation and oxidation can be 


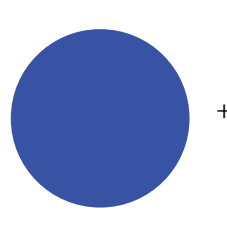

$\mathrm{CuSO}_{4} \cdot 5 \mathrm{H}_{2} \mathrm{O}$

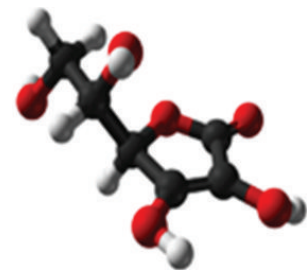

Ascorbic acid

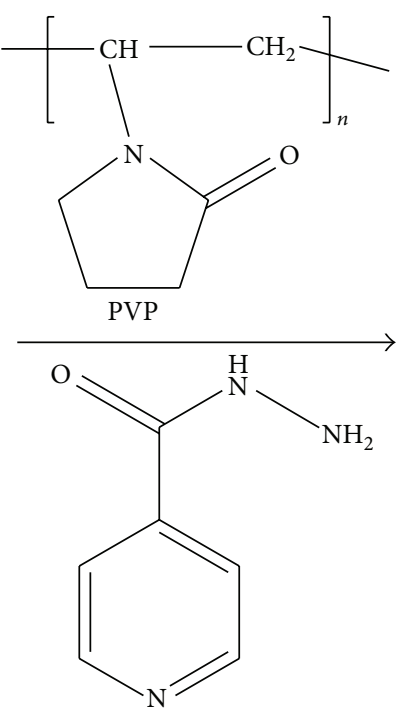

Isoniazid

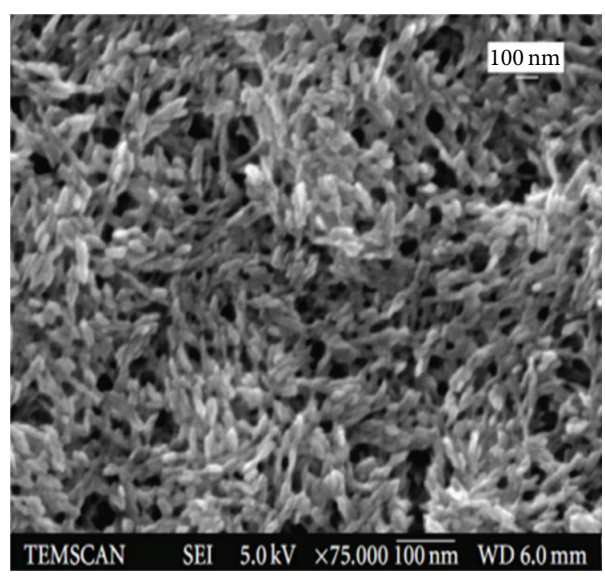

Jasmine bud-shaped Cu NPs

SCHEME 1: Schematic illustration of synthesis of jasmine bud shaped copper nanoparticles. Copper sulfate reacts with PVP to form a complex which is reduced by ascorbic acid and isoniazid resulting in copper nanobuds.

circumvented by the use of various protecting agents such as polymers $[23,24]$ and organic ligands. The usefulness of $\mathrm{Cu}$ as an antibacterial agent has been known for a long time. It is an effective agent with low toxicity, which is especially important in the typical antibacterial treatment.

In recent years with the development of various new nanomaterials, the environmental concerns pertaining to the synthesis and environmental impacts of synthetic nanoparticles are also mounting. To ensure future sustainable development and applications of nanotechnologies, it is essential to implement the principles of green chemistry in every aspect of the nanotechnology from material manufacturing to the environmental fate of the nanomaterials [25]. Sastry et al. have reported green synthesis of $\mathrm{Cu}$ NPs using nontoxic and inexpensive materials like curd, milk, and herbal extracts such as tamarind and lemon juice as capping agents [26]. Typically strong reducing agents such as sodium borohydride and hydrazine are employed to prepare copper nanoparticles. These strong reducing agents create pollution associated with manufacturing of chemicals and the harmful byproducts from the particle fabrication. In the production of copper nanoparticles, the use of environmentally harmful chemicals and the associated environmental risks are minimized. In this report, the synthesis of copper nanobuds by green chemical reduction using isonicotinic acid hydrazide is described. Polyvinyl alcohol has been used as a capping agent and ascorbic acid, which is a naturally occurring material, and has been used as an antioxidant for the preparation of copper nanoparticles. The reducing nature of isoniazid, which is a biocompatible anti-TB drug, was considered to be advantageous over other reducing agents to avoid slow reaction kinetics that eliminates the formation of copper oxide nanoparticles. To the best of our knowledge, this is the first report on the green synthesis of copper nanobuds using isonicotinic acid hydrazide. The copper nanoparticles have good antibacterial activity and antimicrobial formulations comprising nanoparticles could be used as an effective bactericidal agent [27-32].

\section{Materials and Methods}

2.1. Chemicals. Copper (II) sulfate pentahydrate (Merck, purity: 99\%), isonicotinic acid hydrazide (Fluka, purity: 99\%), L-ascorbic acid (S.D.Fine Chemicals, purity: 99\%) and sodium hydroxide (Thomas Baker, purity: 97.5\%), polyvinylpyrrolidone (Aldrich, purity: 98-99\%) were used without further purification. All the reactions were carried out by using double distilled water.

\subsection{Synthesis of Jasmine Bud-Shaped Copper Nanoparticles.}

The copper nanoparticles were synthesized by the following method (Scheme 1). In a typical procedure, the aqueous solution of copper (II) sulfate pentahydrate $(0.01 \mathrm{M})$ was prepared by dissolving this substance in Milli- $\mathrm{Q}$ water $(10 \mathrm{~mL})$, and then it was added to a solution of $1 \%$ PVP $(10 \mathrm{~mL})$. Then, the solution of $\mathrm{NaOH}(0.5 \mathrm{M})$ in deionized water was added dropwise to adjust the $\mathrm{pH}$ to 7 . The reaction mixture was continuously stirred for $1 \mathrm{~h}$. Ascorbic acid $(60 \mathrm{mg})$ was dissolved in $10 \mathrm{~mL}$ deionized water. After stirring at room temperature for $1 \mathrm{~h}$ in presence of air, the mixture was kept at $60-70^{\circ} \mathrm{C}$ for about $10 \mathrm{~min}$. The ascorbic acid was added dropwise to this reaction mixture. The color of the solution turns yellow indicating the formation of copper nanoseeds. Isoniazid $(0.001 \mathrm{M})$ was gradually added to this solution. The color of the reaction mixture changes to reddish brown suggesting the formation of copper nanobuds. Heating and stirring were maintained for further one hour in order to promote the growth of nanobuds. The solution was centrifuged 


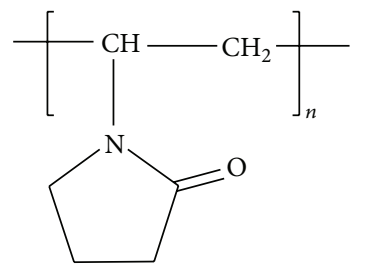

PVP
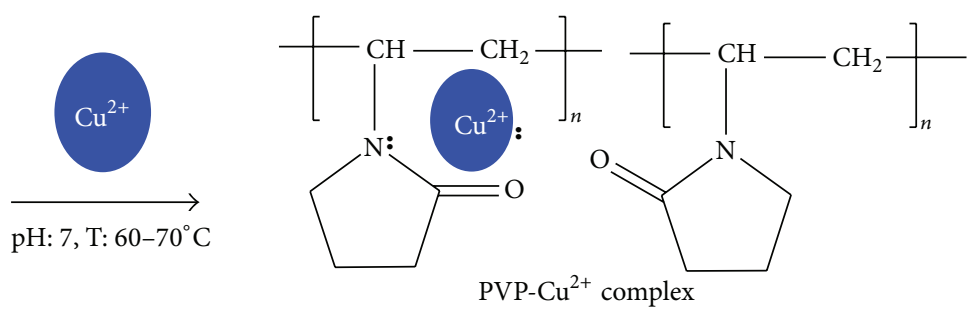

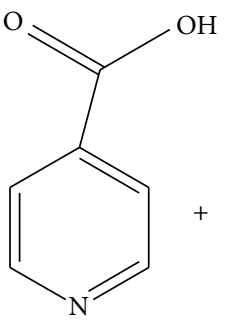

Isonicotinic acid

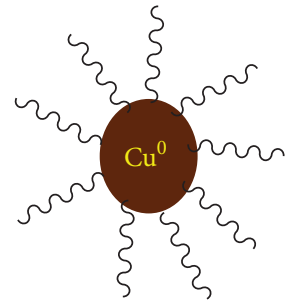

Copper nanobuds

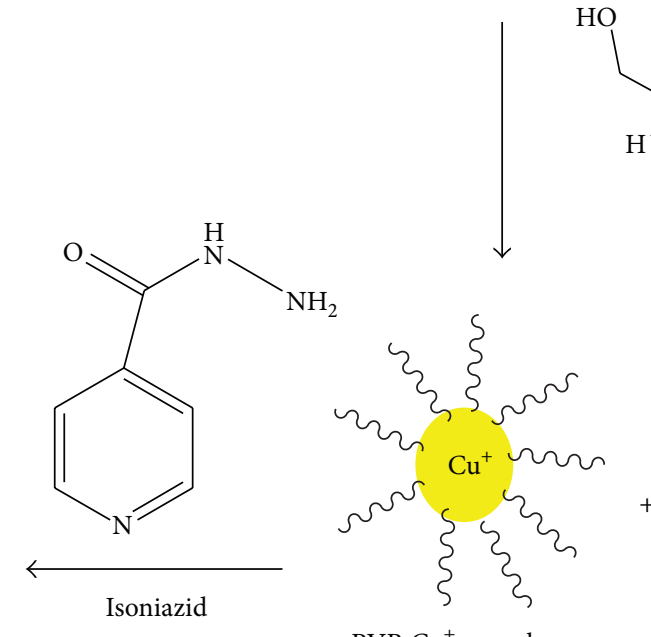

PVP-Cu ${ }^{+}$complex<smiles>O=C1OC(C(O)CO)C(O)=C1O</smiles>

AA<smiles>O=C1OC(C(O)CO)C(O)C1=O</smiles>

Semidehydroascorbate

PVP: Polyvinylpyrrolidone

$\mathrm{Cu}^{2+}$ : Copper sulfate

AA: Ascorbic acid $\sim \Omega$ :

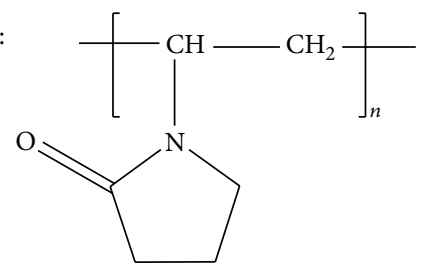

Scheme 2: Mechanism of the formation of copper nanobuds. Copper sulfate forms a complex with PVP when the solution is maintained at $\mathrm{pH}-7\left(60-70^{\circ} \mathrm{C}\right)$. The solution turns yellow after the addition of ascorbic acid indicating the formation of $\mathrm{Cu}(\mathrm{I})$. INH was added dropwise to this reaction mixture resulting in jasmine bud-shaped copper nanoparticles.

at $8,000 \mathrm{rpm}$ for $30 \mathrm{~min}$. The product was washed twice with ethanol and dried under vacuum.

\subsection{Antibacterial Studies. Escherichia coli (E. coli) and} Staphylococcus aureus (S. aureus) were used for the antibacterial study by well diffusion method. Nutrient agar plates were prepared and incubated overnight to check for contamination and the bacterial suspension was grown overnight in nutrient broth. $4 \mathrm{~mm}$ diameter wells were made on the contamination free agar plates with the help of a gel punch. Bacterial suspension was swabbed on the surface of the plates with sterile cotton swabs. Control experiments were also carried out in the presence of ampicillin. $50 \mu \mathrm{g} / \mathrm{mL}$ and $100 \mu \mathrm{g} / \mathrm{mL}$ copper nanoparticles were prepared and $10 \mu \mathrm{L}$ of copper nanoparticles inoculated aseptically to the individual wells.
2.4. Characterization. The copper nanoparticles were characterized by following studies. The UV-Vis spectra were recorded on a Shimadzu UV-1800 UV-Vis spectrophotometer. Powder X-ray diffraction (XRD) analysis was carried out on a Shimadzu XD-D1 XRD unit with a nickel-filtered $\mathrm{Cu}$ $\mathrm{K} \alpha$ radiation at a scanning speed of $1^{\circ} / \mathrm{min}$. Transmission electron microscopy (TEM) images were obtained using the JEOL 100 CXII microscope. Samples for transmission electron microscopy (TEM) were prepared by keeping a drop of the colloidal solution on a copper grid. Samples were dried and kept under vacuum in desiccator before placing them in a specimen holder. The atomic force microscope (AFM) images were recorded under ambient condition using tapping mode of a multimode imaging unit, SPA-400 (Seiko Instruments Inc., Japan) equipped with a controller SPA-4000. The AFM was used to visualize the surface morphology of the samples. 


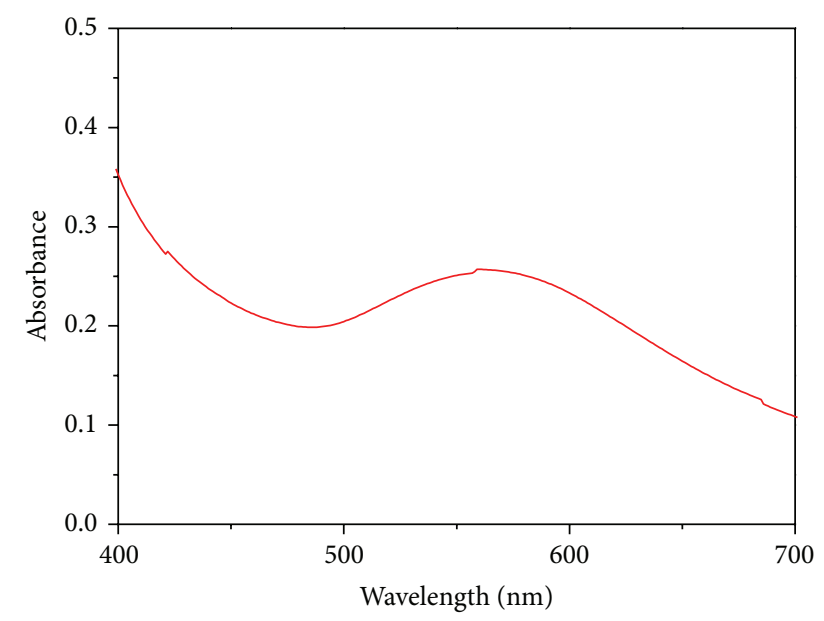

Figure 1: UV-Vis spectrum of copper nanobuds dispersed in deionized water at room temperature exhibiting a peak at $573 \mathrm{~nm}$.

\section{Results and Discussion}

In the present work, $\mathrm{Cu}$ nanoparticles were synthesized by the reduction of $\mathrm{Cu}^{2+}$ using INH (Scheme 2). PVP is also known to be an excellent capping agent to prevent agglomeration and precipitation of the particles; it has been frequently employed as stabilizers in chemical synthesis of metal nanoparticles. The structure of PVP has a polyvinyl skeleton with nitrogen and oxygen polar groups, and the polar groups of PVP can occupy the hybrid orbitals of the copper ion to form a $\mathrm{Cu}^{2+}$-PVP complex. The temperature of the solution was maintained at $60-70^{\circ} \mathrm{C}$. The effect of temperature on the synthesis of hydrophilic CuNPs was reported by khanna et al. [33].

When the solution $\mathrm{pH}$ was maintained at 7.0, the formation of $\mathrm{Cu}(\mathrm{OH})_{2}$ was observed in the solution, similar to the observation made by Liu et al. [34]. Ascorbic acid is a mild reducing agent as well as an antioxidant. Ascorbic acid is essential to avoid the oxidation of copper nanoparticles during the synthesis and in storage. The antioxidant property of ascorbic acid is attributed to its ability to scavenge free radicals and reactive oxygen species [35], accompanying the donation of electron to give the semidehydroascorbate. The $\mathrm{Cu}^{2+}$-PVP complex was reduced to $\mathrm{Cu}^{+}$-PVP complex. It forms yellow color $\mathrm{Cu}$ nanoseeds in the synthesis. As PVP molecule is strongly adsorbed on as-prepared copper nanobuds, they effectively prevent the aggregation in the reduced copper ions. Isoniazid is highly water soluble and a biocompatible compound. It is a mild reducing agent with a hydrazide group that helps in terminating the particle growth resulting in the formation of nanobuds $\left(\mathrm{Cu}^{0}\right.$-PVP). The formation of copper nanobuds is indicated by the change of color from yellow to brown. INH serves as a stable donor and is converted into isonicotinic acid. It reduces the particles size below $10 \mathrm{~nm}$ which is stable for more than one month. AA and INH together constitute the system which is sufficient to reduce $\mathrm{Cu}^{2+}$ to $\mathrm{Cu}^{0}$. Copper nanobuds were obtained for the first time by the application of INH.

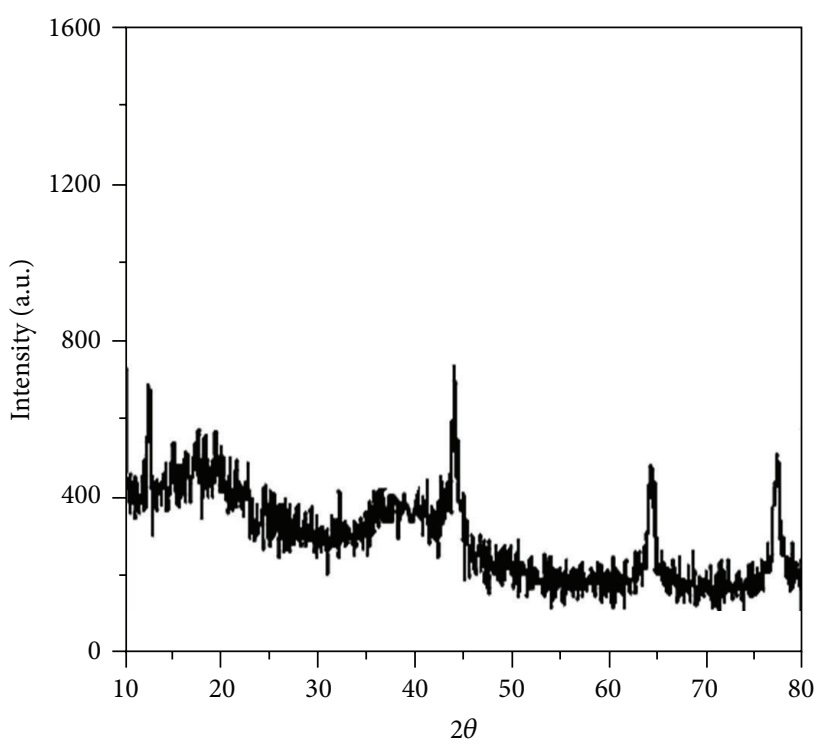

FIGURE 2: XRD pattern of PVP stabilized copper nanobuds exhibits $2 \theta$ values from $40^{\circ}$ to $80^{\circ}$. The fcc structure of $\mathrm{Cu}$ nanobuds shows the average particle size $6.95 \mathrm{~nm}$.

Figure 1 displays the UV-Vis spectrum of $\mathrm{Cu}$ Nps. The characteristic plasmon absorption band for copper nanobuds was observed at $573 \mathrm{~nm}$. The surface plasmon resonance band for copper nanoparticles was located around 560-570 nm and it has been reported to undergo blueshift with decrease in size [36]. When the particles are spherical, the surface plasmon resonance and the blueshift are affected by the size distribution. Hence, it is suggested that the band observed at $573 \mathrm{~nm}$ is due to the copper nanobuds.

Stable $\mathrm{Cu}$ nanobuds, with sizes in the range of $10 \mathrm{~nm}$, have been successfully synthesized using the green chemical reduction method. $\mathrm{Cu}$ Nps have been synthesized using different precursors and the spectral and microscopic data have been reported [37]. In the present investigation, $\mathrm{Cu}$ nanobuds have been prepared by a green chemical reduction method using copper sulfate pentahydrate as a precursor.

The XRD of $\mathrm{Cu}$ nanobuds exhibits peak at $43.6^{\circ}$ and $77.7^{\circ}$ corresponding to $\{111\}$ and $\{220\}$ planes of fcc structure of copper nanoparticles, whereas the $64.5^{\circ}\{220\}$ plane indicates $\mathrm{Cu}_{2} \mathrm{O}$ impurities. The XRD pattern is identified to be that of $\mathrm{Cu}$ Nps, as shown in Figure 2, with trace impurities of $\mathrm{Cu}_{2} \mathrm{O}$. All possible peaks of $\mathrm{Cu} \mathrm{Nps}$ are assigned, in comparison with those described in the literature (JCPDS No-4-0836). Moderate temperature results in intensifying and sharpening of the diffraction peaks. This indicates the growth of $\mathrm{Cu}$ Nps grains and the nanobuds quality is improved. When the temperature is maintained at $60-70^{\circ} \mathrm{C}$, the $\mathrm{Cu}$ nanobuds are formed. During the process of chemical reduction, the precursor decomposes to generate a nucleus of the crystal at first, and then the crystal grain grows during the thermal treatment. Thus, we can say that varying the treatment temperature can control the size of $\mathrm{Cu}$ nanobuds. We also use other starting materials (which are not reported here) to synthesize $\mathrm{Cu}$ nanobuds by the chemical reduction method. 


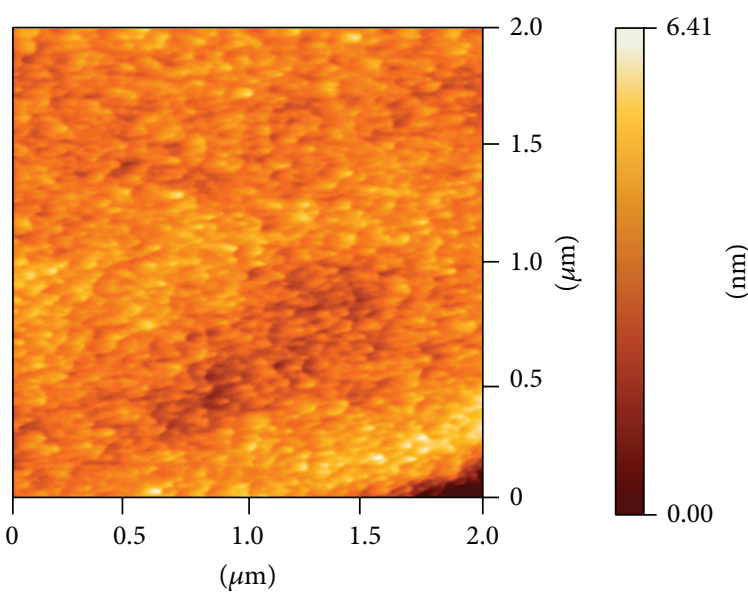

FIgURE 3: AFM 2D images of PVP capped copper nanobuds. The height of the single nanobud is $6.41 \mathrm{~nm}$ as measured in noncontact mode.

In fact, using precursor copper sulfate pentahydrate can result in the smallest and highest quality Cu nanobuds.

Debye-Scherrer equation is

$$
D=\frac{0.9 \lambda}{\beta \cos \theta},
$$

where $D$ is the average size of $\mathrm{Cu} \mathrm{Nps}, \lambda$ is wavelength ( $1.5409 \AA), \beta$ is full width at half maximum, and $\theta$ is diffraction angle.

The size of crystallite estimated from Debye-Scherrer equation is about $6.95 \mathrm{~nm}$, which may indicate a high surface area and surface area to volume ratio of the nanobuds.

Atomic force microscopy (AFM) is the technique that allows measuring interactions between various surfaces and a sharp stylus, tip. The AFM is becoming an important biophysical technique for studying the morphology of nanoparticles and biomolecules. The height and the structure of the copper nanoparticles were investigated with AFM and it indicates that the nanoparticles are bud-like in shape. The results noted in TEM images are quite agreeable to AFM observations. The shape of the copper Nps is similar to jasmine buds and the height of this particular sample is $6.41 \mathrm{~nm}$ (Figure 3).

TEM image for $\mathrm{Cu}$ nanobuds synthesized from copper sulfate is illustrated in Figure 4. It shows that copper nanoparticles exhibit bud-shape. The average particle size is approximately $7 \mathrm{~nm}$, which is in good agreement with the XRD results. The XRD technique appears to slightly underestimate the particle size in the present case. The TEM image in Figure 4 indicates clearly that each particle has a bud structure.

Copper nanoparticles and the type of microorganism play an important role in the antibacterial activity [38]. The toxicity of copper nanoparticles depends on the combination of several factors such as temperature, concentration of $\mathrm{NPs}, \mathrm{pH}$, and concentration of bacteria [39]. The copper nanoparticles were tested against the Gram-negative bacterial strain E. coli and the Gram-positive strain S. aureus by well diffusion method to evaluate the antimicrobial activity of

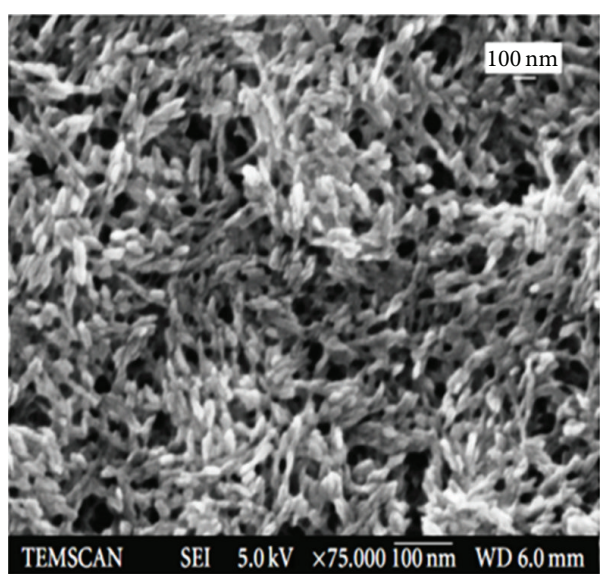

FIGURE 4: TEM images illustrate the formation of jasmine budshaped PVP capped copper nanoparticles in $100 \mathrm{~nm}$ scale.

copper nanoparticles. $4 \mathrm{~mm}$ diameter wells were made on the contamination free agar plates with the help of a gel punch. Bacterial suspension was swabbed on the surface of the plates with sterile cotton swabs. Control experiments were also carried out in the presence of ampicillin. Copper nanoparticles with different concentrations $(50 \mu \mathrm{g} / \mathrm{mL}$ and $100 \mu \mathrm{g} / \mathrm{mL}$ ) were prepared and $10 \mu \mathrm{L}$ of copper nanoparticles inoculated aseptically to the individual wells. The inoculated sets were incubated at $37^{\circ} \mathrm{C}$ for $24 \mathrm{~h}$. The experiments were carried out in triplicates. The effectiveness of an antimicrobial agent is based on the zones of inhibition. The diameter of the zone is measured to the nearest millimeter $(\mathrm{mm})$. The zone of inhibition for the E. coli strain for different concentrations of copper nanoparticles is $17(50 \mu \mathrm{g} / \mathrm{mL})$ and $23 \mathrm{~mm}(100 \mu \mathrm{g} / \mathrm{mL})$, respectively, while that of the S. aureus strain are $21(50 \mu \mathrm{g} / \mathrm{mL})$ and $28 \mathrm{~mm}(100 \mu \mathrm{g} / \mathrm{mL})$, respectively (Figure 5). The increase in concentration of NPs leads to higher toxicity and hence increase in the zone of inhibition. Metallic and ionic forms of copper produce hydroxyl radicals that damage essential proteins and DNA [40]. Lee et al. have reported biological synthesis of copper nanoparticles which exhibit high antibacterial activity against Gram-negative bacterium [41].

\section{Conclusions}

In summary, the novel jasmine bud-shaped $\mathrm{Cu}$ nanoparticles have been prepared by a green chemical reduction method from copper sulfate precursor. The $\mathrm{Cu}$ nanobuds were characterized by means of UV-Vis spectroscopy, XRD, TEM, and AFM and their antimicrobial activity has also been investigated. The results show that the $\mathrm{Cu}$ nanoparticles have jasmine bud-shapes and their average particle size obtained from XRD study is $6.95 \mathrm{~nm}$. The presence of UV-Vis absorption peak at $573 \mathrm{~nm}$ is attributed to the formation of copper nanobuds which is confirmed by the TEM study. Copper nanobuds synthesized in the present investigation exhibit good antibacterial activity against the human pathogens $E$. coli and S. aureus. 


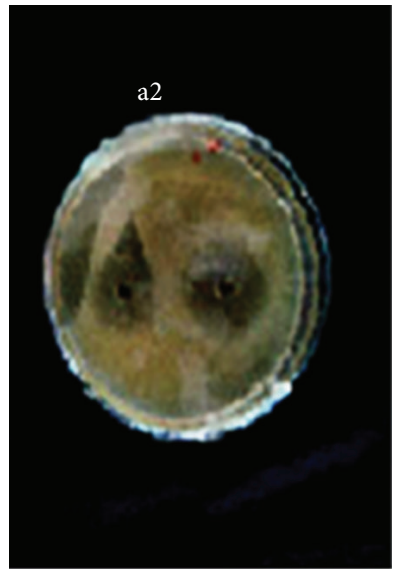

(a)

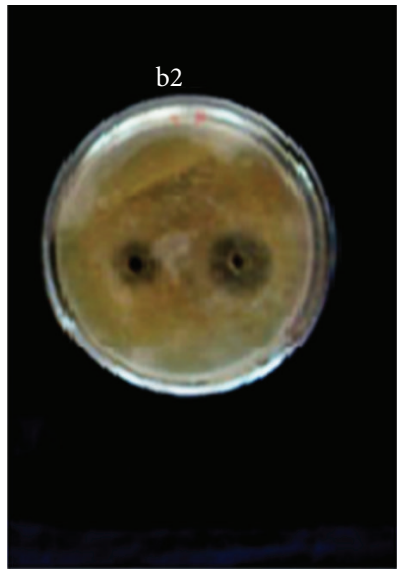

(b)

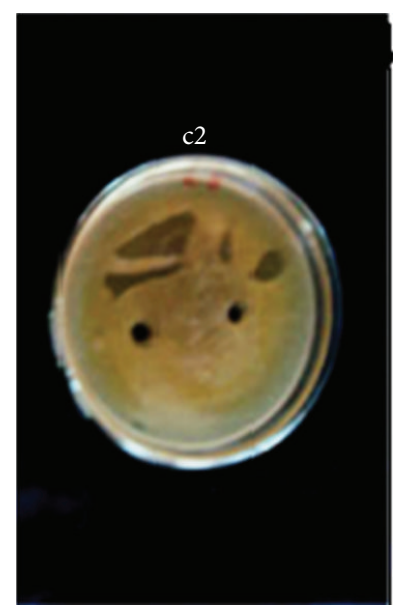

(c)

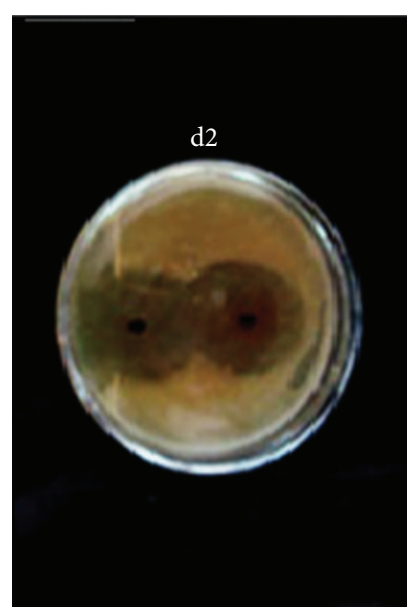

(d)

FIGURE 5: Zone of inhibition by copper nanoparticles (jasmine bud-shaped) against human pathogens-(a) Escherichia coli, (b) Staphylococcus aureus, (c) solvent, (d) ampicillin.

\section{Conflict of Interests}

The authors report no conflict of interests in this work.

\section{Acknowledgments}

The authors thank National Center for Nanoscience and Nanotechnology (NCNST), University of Madras, for TEM study. The financial support by the Indian Council of Medical Research (ICMR), New Delhi, is gratefully acknowledged.

\section{References}

[1] B. White, M. Yin, A. Hall et al., "Complete CO oxidation over $\mathrm{Cu}_{2} \mathrm{O}$ nanoparticles supported on silica gel," Nano Letters, vol. 6, no. 9, pp. 2095-2098, 2006.

[2] T. M. D. Dang, T. T. T. Le, E. Fribourg-Blanc, and M. C. Dang, "Synthesis and optical properties of copper nanoparticles prepared by a chemical reduction method," Advances in Natural Sciences, vol. 2, Article ID 015009, pp. 1-6, 2011.

[3] S. A. Majetich and Y. Jin, "Magnetization directions of individual nanoparticles," Science, vol. 284, no. 5413, pp. 470-473, 1999.

[4] M. Dorogi, J. Gomez, R. Osifchin, R. P. Andres, and R. Reifenberger, "Room-temperature Coulomb blockade from a self-assembled molecular nanostructure," Physical Review B, vol. 52, no. 12, pp. 9071-9077, 1995.

[5] L. Guczi, "Bimetallic nano-particles: featuring structure and reactivity," Catalysis Today, vol. 101, no. 2, pp. 53-64, 2005.

[6] T. N. Rostovshchikova, V. V. Smirnov, V. M. Kozhevin et al., "New size effect in the catalysis by interacting copper nanoparticles," Applied Catalysis A, vol. 296, no. 1, pp. 70-79, 2005.

[7] S. S. Joshi, S. F. Patil, V. Iyer, and S. Mahumuni, "Radiation induced synthesis and characterization of copper nanoparticles," Nanostructured Materials, vol. 10, no. 7, pp. 1135-1144, 1998.

[8] M. S. Yeh, Y. S. Yang, Y. P. Lee, H. F. Lee, Y. Yeh, and C. Yeh, "Formation and characteristics of $\mathrm{Cu}$ colloids from $\mathrm{CuO}$ powder by laser irradiation in 2-propanol," Journal of Physical Chemistry B, vol. 103, no. 33, pp. 6851-6857, 1999.
[9] Y. H. Kim, D. K. Lee, B. G. Jo, J. H. Jeong, and Y. S. Kang, "Synthesis of oleate capped $\mathrm{Cu}$ nanoparticles by thermal decomposition," Colloids and Surfaces A, vol. 284-285, pp. 364$368,2006$.

[10] J. Hambrock, R. Becker, A. Birkner, J. Weiß, and R. A. Fischer, "A non-aqueous organometallic route to highly monodispersed copper nanoparticles using $\left[\mathrm{Cu}\left(\mathrm{OCH}(\mathrm{Me}) \mathrm{CH}_{2} \mathrm{NME}_{2}\right)_{2}\right]$," Chemical Communications, no. 1, pp. 68-69, 2002.

[11] K. J. Ziegler, R. C. Doty, K. P. Johnston, and B. A. Korgel, "Synthesis of organic monolayer-stabilized copper nanocrystals in supercritical water," Journal of the American Chemical Society, vol. 123, no. 32, pp. 7797-7803, 2001.

[12] S. K. Haram, A. R. Mahadeshwar, and S. G. Dixit, "Synthesis and characterization of copper sulfide nanoparticles in triton-X 100 water-in-oil microemulsions," Journal of Physical Chemistry, vol. 100, no. 14, pp. 5868-5873, 1996.

[13] I. Lisiecki, M. Björling, L. Motte, B. Ninham, and M. P. Pileni, "Synthesis of copper nanosize particles in anionic reverse micelles: effect of the addition of a cationic surfactant on the size of the crystallites," Langmuir, vol. 11, no. 7, pp. 2385-2392, 1995.

[14] A. A. Ponce and K. J. Klabunde, "Chemical and catalytic activity of copper nanoparticles prepared via metal vapor synthesis," Journal of Molecular Catalysis A, vol. 225, no. 1, pp. 1-6, 2005.

[15] I. Haas, S. Shanmugam, and A. Gedanken, "Pulsed sonoelectrochemical synthesis of size-controlled copper nanoparticles stabilized by poly(N-vinylpyrrolidone)," Journal of Physical Chemistry B, vol. 110, no. 34, pp. 16947-16952, 2006.

[16] E. K. Athanassiou, R. N. Grass, and W. J. Stark, "Large-scale production of carbon-coated copper nanoparticles for sensor applications," Nanotechnology, vol. 17, no. 6, pp. 1668-1673, 2006.

[17] L. Chen, D. Zhang, J. Chen, H. Zhou, and H. Wan, "The use of CTAB to control the size of copper nanoparticles and the concentration of alkylthiols on their surfaces," Materials Science and Engineering A, vol. 415, no. 1-2, pp. 156-161, 2006.

[18] T. P. Ang, T. S. A. Wee, and W. S. Chin, "Three-dimensional selfassembled monolayer (3D SAM) of n-alkanethiols on copper nanoclusters," Journal of Physical Chemistry B, vol. 108, no. 30, pp. 11001-11010, 2004. 
[19] A. A. Athawale, P. P. Katre, M. Kumar, and M. B. Majumdar, "Synthesis of CTAB-IPA reduced copper nanoparticles," Materials Chemistry and Physics, vol. 91, no. 2-3, pp. 507-512, 2005.

[20] A. Yanase and H. Komiyama, "In situ observation of oxidation and reduction of small supported copper particles using optical absorption and X-ray diffraction," Surface Science, vol. 248, no. 1-2, pp. 11-19, 1991.

[21] S.-H. Wu and D.-H. Chen, "Synthesis of high-concentration Cu nanoparticles in aqueous CTAB solutions," Journal of Colloid and Interface Science, vol. 273, no. 1, pp. 165-169, 2004.

[22] D. B. Pedersen, S. Wang, and S. H. Liang, "Charge-transferdriven diffusion processes in $\mathrm{Cu@Cu-oxide} \mathrm{core-shell} \mathrm{nanopar-}$ ticles: oxidation of $3.0 \pm 0.3 \mathrm{~nm}$ diameter copper nanoparticles," Journal of Physical Chemistry C, vol. 112, no. 24, pp. 8819-8826, 2008.

[23] R. M. Crooks, M. Zhao, L. Sun, V. Chechik, and L. K. Yeung, "Dendrimer-encapsulated metal nanoparticles: synthesis, characterization, and applications to catalysis," Accounts of Chemical Research, vol. 34, no. 3, pp. 181-190, 2001.

[24] L. Balogh and D. A. Tomalia, "Poly(amidoamine) dendrimertemplated nanocomposites. 1. Synthesis of zerovalent copper nanoclusters," Journal of the American Chemical Society, vol. 120, no. 29, pp. 7355-7356, 1998.

[25] J. A. Dahl, B. L. S. Maddux, and J. E. Hutchison, "Toward greener nanosynthesis," Chemical Reviews, vol. 107, no. 6, pp. 2228-2269, 2007.

[26] A. B. S. Sastry, R. B. Karthik Aamanchi, Ch. Rama Linga Prasad, and B. S. Murthy, "Large-scale green synthesis of $\mathrm{Cu}$ nanoparticles," Environmental Chemistry Letters, vol. 11, no. 2, pp. 183-187, 2013.

[27] P. K. Stoimenov, R. L. Klinger, G. L. Marchin, and K. J. Klabunde, "Metal oxide nanoparticles as bactericidal agents," Langmuir, vol. 18, no. 17, pp. 6679-6686, 2002.

[28] S. Ravikumar, R. Gokulakrishnan, K. Selvanathan, and S. Selvam, "Antibacterial activity of metal oxide nanoparticles against ophthalmic pathogens," International Journal of Pharmaceutical Research and Development, vol. 3, no. 5, pp. 122-127, 2011.

[29] R. Rajendran, C. Balakumar, A. M. A. Hasabo, S. Jayakumar, K. Vaideki, and E. M. Rajesh, "Use of zinc oxide nanoparticles for production of antimicrobial textiles," International Journal of Engineering Science and Technology, vol. 2, no. 1, pp. 202-208, 2010.

[30] N. Padmavathy and R. Vijayaraghavan, "Enhanced bioactivity of $\mathrm{ZnO}$ nanoparticles-an antimicrobial study," Science and Technology of Advanced Materials, vol. 9, no. 3, Article ID 035004, p. 7, 2008.

[31] P. Hosseinkhani, A. M. Zand, S. Imani, M. Rezayi, and S. R. Zarchi, "Determining the antibacterial effect of $\mathrm{ZnO}$ nanoparticle against the pathogenic bacterium, Shigella dysenteriae (type 1)," International Journal of Nano Dimension, vol. 1, no. 4, pp. 279-285, 2011.

[32] S. Jadhav, S. Gaikwad, M. Nimse, and A. Rajbhoj, "Copper oxide nanoparticles: synthesis, characterization and their antibacterial activity," Journal of Cluster Science, vol. 22, no. 2, pp. 121-129, 2011.

[33] P. K. Khanna, P. More, J. Jawalkar, Y. Patil, and N. Koteswar Rao, "Synthesis of hydrophilic copper nanoparticles: effect of reaction temperature," Journal of Nanoparticle Research, vol. 11, no. 4, pp. 793-799, 2009.

[34] Q.-M. Liu, T. Yasunami, and K. Kuruda, "Preparation of Cu nanoparticles with ascorbic acid by aqueous solution reduction method," Transactions of Nonferrous Metals Society of China, vol. 22, no. 9, pp. 2198-2203, 2012.

[35] W. Yu, H. Xie, L. Chen, Y. Li, and C. Zhang, "Synthesis and characterization of monodispersed copper colloids in polar solvents," Nanoscale Research Letters, vol. 4, no. 5, pp. 465-470, 2009.

[36] A. Moores and F. Goettmann, "The plasmon band in noble metal nanoparticles: an introduction to theory and applications," New Journal of Chemistry, vol. 30, no. 8, pp. 1121-1132, 2006.

[37] X. Song, S. Sun, W. Zhang, and Z. Yin, "A method for the synthesis of spherical copper nanoparticles in the organic phase," Journal of Colloid and Interface Science, vol. 273, no. 2, pp. 463-469, 2004.

[38] B. Jia, Y. Mei, L. Cheng, J. Zhou, and L. Zhang, "Preparation of copper nanoparticles coated cellulose films with antibacterial properties through one-step reduction," ACS Applied Material Interface, vol. 4, pp. 2897-2902, 2012.

[39] M. J. Hajipour, K. M. Fromm, A. A. Ashkarrn et al., "Antibacterial properties of nanoparticles," Trends in Biotechnology, vol. 30, no. 10, pp. 499-511, 2012.

[40] S. Wang, R. Lawson, P. C. Ray, and H. Yu, "Toxic effects of gold nanoparticles on Salmonella typhimurium bacteria," Toxicology and Industrial Health, vol. 27, no. 6, pp. 547-554, 2011.

[41] H.-J. Lee, J. Y. Song, and B. S. Kim, "Biological synthesis of copper nanoparticles using Magnolia kobus leaf extract and their antibacterial activity," Journal of Chemical Technology and Biotechnology, vol. 88, no. 11, pp. 1971-1977, 2013. 

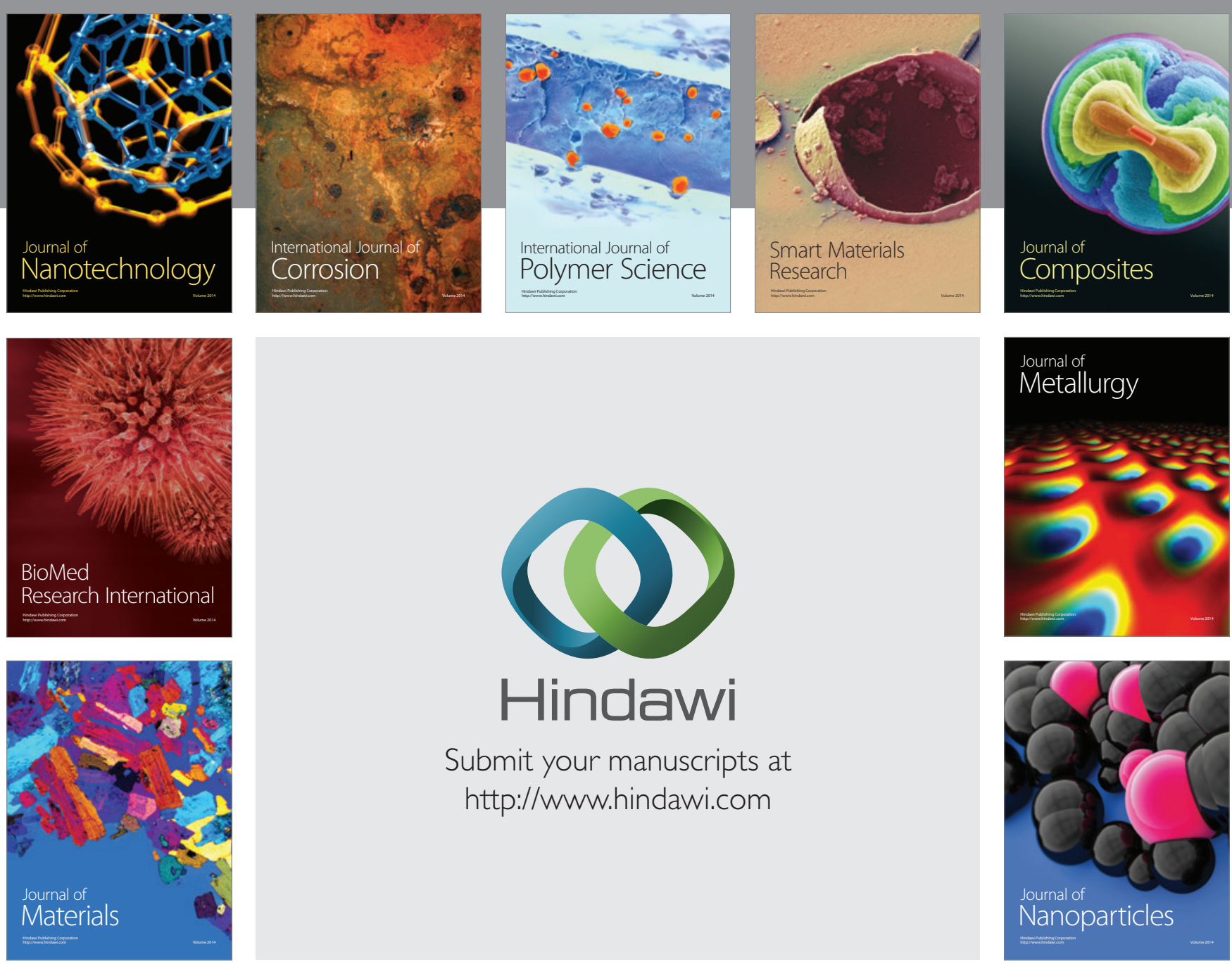

Submit your manuscripts at http://www.hindawi.com
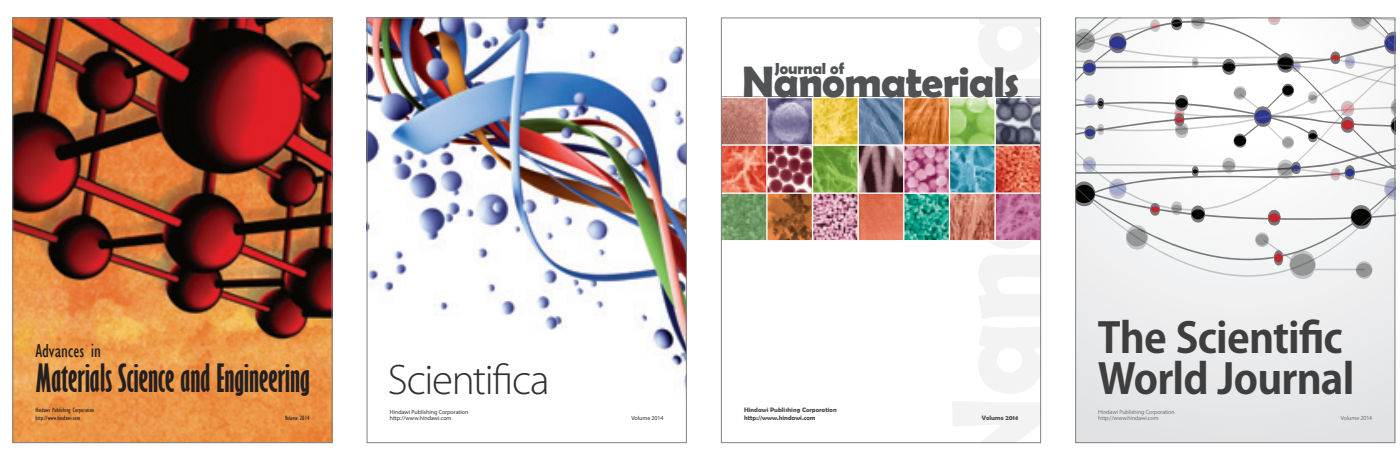

\section{The Scientific World Journal}
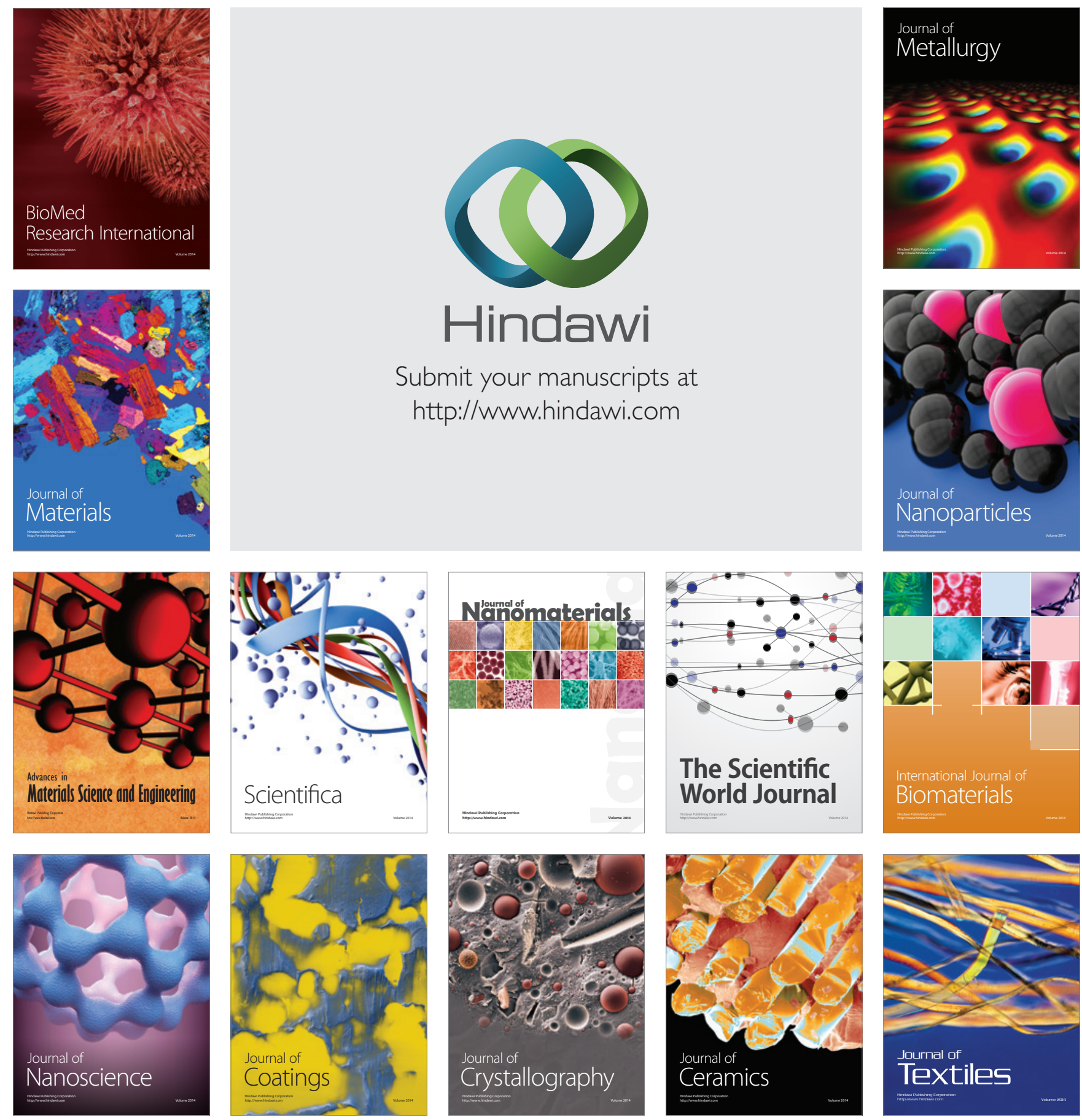